\title{
Open Heart Surgery Associated Acute Kidney Injury in Children
}

\author{
Jekabs Krastins*, Zane Straume*, Janis Auzins*, Aigars Petersonss**, Aivars Petersons*** \\ *Pediatric Intensive Care, University Children's Hospital, Riga, Latvia \\ **Department of Pediatric Surgery, Riga Stradin's University, Latvia \\ ***Centre of Nephrology, Department of Internal diseases, Riga Stradin's University, Latvia
}

\begin{abstract}
Summary.
Introduction. Cardiac surgery with cardiopulmonary bypass (CPB) is commonly perceived as a risk factor for decline in renal function. Hypothermia, hypoxia, hypotension, non-pulsatile blood flow during CPB, use of ACE inhibitors, inotropic and (or) vasoactive support affects kidney and contributes to the acute kidney injury (AKI).

Aim of the study. The purpose of this study was to evaluate the incidence, severity and outcome of CPB related AKI in children after open heart surgery.

Materials and methods. We conducted prospective, non-randomized observational study at the tertiary care University Children's Hospital Pediatric ICU. We enrolled 30 patients, 12 boys and 18 girls with congenital heart disease (CHD). Their median body weight was $6,8 \mathrm{~kg}$, (IQR 5,2<8,2 kg) and median age 7 months (IQR $5<10$ months). SCr was determined and preoperative and postoperative creatinine clearance $(\mathrm{ClCr})$ was estimated using Schwarz formula (eClCr). During surgical repair and till the end of the first 12 postoperative hours urine was collected to measure $\mathrm{CICr}$, using the difference in urine $(\mathrm{UCr})$ and $\mathrm{SCr}$ concentrations (mCICr). Urine output, body temperature, duration of aortic cross clamping and cardiopulmonary bypass was recorded.

Results. Median intraoperative urine output was 2,4 ml/kg/h (IQR 1,29<3,15 ml/kg/h). Median CPB time was $147 \mathrm{~min}$., (IQR $116,75<205$ min.), median aortic cross-clamping time was 95 min., (IQR 70,5<133 min.), cooling during CPB to $29,75^{\circ} \mathrm{C}$. Postoperative SCr increased to $35 \mu \mathrm{mol} / \mathrm{I}(\mathrm{IQR} 27,5<50,5 \mu \mathrm{mol} / \mathrm{l})$ vs. preoperative SCr $29 \mu \mathrm{mol} / \mathrm{l}(\mathrm{IQR} 24<32,9 \mu \mathrm{mol} / \mathrm{I}), \mathrm{P}<0,0001$. GFR declined from preoperative $98,4 \mathrm{ml} / \mathrm{min} . / 1,73 \mathrm{~m} 2$ (IQR 89,6<123,04) to postoperative $80,98 \mathrm{ml} / \mathrm{min} . / 1,73 \mathrm{~m} 2$, (IQR $60,73<97,97 \mathrm{ml} / \mathrm{min} . / 1,73 \mathrm{~m} 2), P<0,0001$. We find statistically significant difference $(\mathrm{P}=0,042)$ in measured $39,88 \mathrm{ml} / \mathrm{min} . / 1,73 \mathrm{~m} 2$ (IQR 21,96<67,82 ml/min./1,73 m2) versus estimated CICr (eCICr) 80,98 ml/min./1,73 m2, (IQR 60,73<97,97 ml/min./1,73 m2). Observed prevalence of AKI was 46,6\% (14/30 patients met KDIGO criteria for AKI).

Conclusions. Open heart surgery in children has severe, but transient effect on expression of renal biomarkers. There was a marked difference between measured and estimated CICr in our patients. Observed incidence of AKI was 46,6\% (14 patients met KDIGO criteria of AKI from 30 of our patients). Before discharge from the hospital both biomarkers returned to normal values.

Keywords: cardiopulmonary bypass, acute kidney injury, renal biomarkers, creatinine clearance, pediatric open heart surgery.
\end{abstract}

\section{INTRODUCTION}

Cardiac surgery with cardiopulmonary bypass $(\mathrm{CPB})$ is commonly perceived as a risk factor for decline in renal function. Acute kidney injury (AKI), depending on the specific definition, occurs in up to $52 \%$ of all patients who undergo open heart surgery (1-15). Renal replacement therapy (RRT) needs approximately $1 \%$ of patients suffering from AKI $(1,2,4)$. The development of kidney injury is associated with a high mortality, a more complicated hospital course, and a higher risk for infectious complications (2). AKI has a notable increased morbidity risk, including longer duration of ventilation and overall length of stay (12). Even minimal changes in serum creatinine that occur in the postoperative period are associated with a substantial decrease in survival (10). Furthermore, the majority of patients who develop AKI that requires dialysis, remain dialysis dependent, leading to significant long-term morbidity and mortality (13). Pediatric patients comprise an ideal and informative population for the study of AKI biomarkers as they do not exhibit common adult confounding factors that complicate similar studies in adults, such as diabetes, hypertension, atherosclerosis, and nephrotoxin use (15).

\section{AIM OF THE STUDY}

Our goal was to evaluate incidence and outcome of AKI in children undergoing open heart surgery and to compare the measured and estimated ClCr. As an indicator of AKI we used perioperative changes in serum creatinine (SCr). KDIGO (Kidney Disease: Improving Global Outcomes) definition was used to assess severity of AKI.

\section{MATERIALS AND METHODS}

We conducted prospective, nonrandomized observational study at the tertiary care University Children's hospital 12-bed surgical ICU during 20102011 years. Study protocol was approved by Hospital Ethics commission. Inclusion criteria: Body weight less than $10 \mathrm{~kg}(1)$ and intact renal functions (2). We enrolled 30 patients, 12 boys and 18 girls with CHD. Their median body weight was $6,8 \mathrm{~kg}$, (IQR 5,2<8,2 $\mathrm{kg}$ ) and median age of 7 months (Table 1). There were 
$15(50 \%)$ patients with ventricular septal defect (VSD), $7(23,4 \%)$ patients had atrioventricular septal defect (AVSD), one $(3,3 \%)$ had total anomalous pulmonary venous drainage (TAPVD), $3(10 \%)$ had Tetrology of Fallot (TOF), $3(10 \%)$ had transposition of great arteries (TGA), and one (3,3\%)-AVSD with tricuspid stenosis (Table 2). The SCr level was determined by Jaffé's method (Cobas 6000 analyzer, Roche) and preoperative and postoperative $\mathrm{ClCr}$ without urine collection was estimated using Schwarz formula [16]: $\mathrm{eCrCl}$ in $\mathrm{ml} / \mathrm{min} / 1,73 \mathrm{~m}^{2}=k \times \mathrm{L} / \mathrm{SCr}$, in which $k$ is proportionality constant $(0,33-0,45$, depending on maturity) and $L$ is length in centimeters. During the surgical repair and till the end of the first 12 hours after surgery urine was collected to measure $\mathrm{ClCr}$, using the difference in urine (UCr) and SCr concentrations, using standard formula: $\mathrm{mCrCl}$ in $\mathrm{ml} / \mathrm{min} / 1,73 \mathrm{~m}^{2}=$ $(\mathrm{UCr} \times$ Urine output $(\mathrm{ml}) /(\mathrm{SCr} \times$ time in hours $\times 60) \times$ $(1,73 / \mathrm{BSA})$, in which UCr is urinary creatinine, $\mathrm{SCr}$ is serum creatinine and BSA is body surface area. Urine output, lowest body temperature during $\mathrm{CPB}$, aortic cross clamping and cardiopulmonary bypass time was recorded.

Statistical methods. Statistics were performed with the help of the statistical software StatPlus ${ }^{\circledR}$ 5.8.2.0 (Analyst Soft Inc). Continuous variables were presented as median and interquartile range (IQR). Dispersion analysis using one-way analysis of variance (ANOVA) test was used to determine the difference between SCr and ClCr values at different time points: Before the surgery (1), on the following morning, $<12$ hours after completion of surgery (2) and before discharge the patient from hospital (3). Continuous data were compared using Student's $t$-test. Pearsons correlation was used to find a correlation between CPB and ClCr. A $p$ value less than 0,05 was considered statistically significant.

\section{RESULTS}

Median CPB time was 147 min., IQR 1 16,75<205 min., median aortic cross-clamping time was $95 \mathrm{~min}$., (IQR $70,5<133 \mathrm{~min}$.), cooling during CPB to $29,75^{\circ} \mathrm{C}$. Median perioperative (from the start of surgery till the following morning $<12$ hours) urine output was $2,4 \mathrm{ml} / \mathrm{kg} / \mathrm{h}$ (IQR $1,29<3,15 \mathrm{ml} / \mathrm{kg} / \mathrm{h}$ ), table 3. Postoperative median SCr raised to $35 \mu \mathrm{mol} / \mathrm{l}$ (IQR 27,5<50,5) versus preoperative median SCr $29 \mu \mathrm{mol} / \mathrm{l}$ (IQR 24<32,9), P<0,0001. GFR declined from preoperative $98,4 \mathrm{ml} / \mathrm{min} . / 1,73 \mathrm{~m}^{2}$ (IQR $89,6<123,04)$ to postoperative $80,98 \mathrm{ml} / \mathrm{min} . / 1,73 \mathrm{~m}^{2}$, (IQR 60,73<97,97 ml/min./1,73 $\mathrm{m}^{2}$ ), $P<0,0001$, (Table 4, Fig. 1,2). We find statistically significant difference $(\mathrm{P}=0,042)$ in measured $39,88 \mathrm{ml} / \mathrm{min} . / 1,73 \mathrm{~m}^{2}$, (IQR $\left.21,96<67,82 \mathrm{ml} / \mathrm{min} . / 1,73 \mathrm{~m}^{2}\right) \mathrm{ClCr}$ and estimated $\mathrm{ClCr}$ (eClCr) $80,98 \mathrm{ml} / \mathrm{min} . / 1,73 \mathrm{~m}^{2}$ (IQR 60,73<97,97 ml/ min./1,73 $\left.\mathrm{m}^{2}\right)$. Schwarz equitation overestimates eClCr $\left(80,98\right.$ vs. $39,88 \mathrm{ml} / \mathrm{min} . / 1,73 \mathrm{~m}^{2}$ (Fig. 3$)$. According to KDIGO definition we detected AKI in $14 / 30(46,6 \%)$ of our patients (Table 5).

\section{DISCUSSION}

The etiology of AKI after CPB is multifactorial and incompletely understood. Various factors related to $\mathrm{CPB}$ have been implicated as possible determinants of AKI. They include hypothermia, hypoxia, hypotension, nonpulsatile blood flow during CPB, use of ACE inhibitors, inotropic and (or) vasoactive support that affects kidney and contributes to the AKI. CPB is associated with significant hemodynamic changes, and the maintenance of cardiovascular stability during CPB requires interplay between the function of the CPB machine and patient factors such as systemic vascular resistance, venous compliance, and autoregulatory capacity of various vascular beds. CPB creates a hemodynamic state of nonpulsatile flow and microembolism. Hemodynamic instability may occur during the transition from full hemodynamic support with CPB to full circulation by the patient's own cardiovascular system. A low-cardiac output state contributes to generalized hypoperfusion and renal ischemia. Length of time on CPB is a wellrecognized risk factor for the development of AKI. The ultimate goal is to maintain regional perfusion at a level that supports optimal cellular and organ function. Thus, any decrease in renal perfusion during CPB, depending on its magnitude and duration, can lead to significant cellular injury. The pathogenesis of cardiac surgery-associated AKI is complex and multifactorial and includes several injury pathways: ischemia and reperfusion, exogenous and endogenous toxins, inflammation, oxidative stress, and hemodynamic factors. These mechanisms of injury are likely to be active at different times with different intensities and probably act synergistically (17). The reported incidence of AKI after pediatric open heart surgery varies from $1,6 \%$ to $52 \%$ depending on definition. To amend this variability, the Acute Dialysis Quality Initiative group standardized the definition of AKI in 2002 using the RIFLE criteria (18). Based on glomerular filtration rate, serum creatinine values, and urine output plotted against time of admission, RIFLE marks progressive degrees of injury in adult patients. In 2004, the Acute Kidney Injury Network defined AKI based on time in relation to absolute creatinine increase, percentage increase, or documented oliguria. The adult-derived RIFLE definition was modified, applied, and validated in studies of critically ill patients (19) and renamed the pediatric RIFLE (pRIFLE) criteria (20). Recently the KDIGO workgroup has reviewed these criteria and published a single definition for use in both clinical practice and research. AKI is defined when any of the following three criteria are met; an increase in serum creatinine by $50 \%$, an increase in serum creatinine $>0.3$ $\mathrm{mg} / \mathrm{dL}$ or oliguria (21). In the study conducted by Liu and colleagues (14) defined AKI was a $50 \%$ or greater increase in serum creatinine from baseline within 3 days. Of the 71 pediatric patients undergoing open heart surgery, AKI developed in 20 patients $(28 \%)$. Krawczeski with coauthors (13) in study of 240 pediatric patients, AKI occurred in $27 \%$ of them. Patients having AKI were younger and had lower baseline SCr. None 
of their patients required RRT. AKI was associated with longer CPB times $(P=0,0005)$ and increased need for mechanical ventilation, $33 \%$ versus $78 \% \quad(P=0,006)$ in patients having AKI. In Bennett's study (8) AKI developed in 99 patients $(51 \%)$. Blinder with colleagues (9) retrospectively studied 430 infants who underwent heart surgery for congenital defects and observed AKI in $52 \%$ of patients. Even in the studies published after introduction of RIFLE and AKIN definitions, variability $(27 \%-52 \%)$ of AKI incidence has been reported $(5,6,8,9,15)$. It was difficult to compare SCr and $\mathrm{ClCr}$ values of various ages due to wide distribution of specific values. ClCr vary from $17 \mathrm{ml} / \mathrm{min} / 1,73 \mathrm{~m}^{2}$ in the first week of life to $157 \mathrm{ml} / \mathrm{min} / 1,73 \mathrm{~m}^{2}$ at 12 months of age (22). To overcome this difficulty we based our study on SCr dynamics (1,5, 2 fold and 3 fold rise in SCr against entry level corresponds to stages 1, 2, and 3 in KDIGO definition (21). In our study group AKI criteria met $46,6 \%(14 / 30)$ of our patients. SCr increase by $50 \%$ $100 \%$ (Median 65,22 $\mu \mathrm{mol} / \mathrm{l}$ ) we detected in 9 patients, more than 2-fold increase in SCr (Median 228,88 $\mu \mathrm{mol} / \mathrm{l}$ ) we find in 5 children (Table 5). In current clinical practice SCr is used for identification and classification of AKI as an essential reference in all AKI definitions. Last years a number of new, more sensitive biomarkers of kidney injury are introduced, tested and validated (23). Kidney injury molecule-1, interleukin-18, and liver fatty acid-binding protein (L-FABP) have been shown to be associated with kidney ischemia (13). Clinical studies indicate urine and serum neutrophil gelatinase-associated lipocalin as highly sensitive, specific, and predictive of AKI in many different disease processes (14). Recently, urinary hepcidin has been suggested as a candidate biomarker of AKI (24). Despite the enthusiasm with novel biomarkers, most of them are still not available for routine clinical practice. In the postoperative care ClCr based estimate of GFR still may be a good biomarker of change in renal function (25). Until recently, most AKI studies have focused on critically ill children who receive some form of RRT. While care for the critically ill child with AKI has improved greatly, with survival rates reaching $60-70 \%$ for children who require renal replacement therapy (26), few data exist to describe the long-term outcomes of survivors of a pediatric AKI episode. Finally, at 3- to 5-year followup, $40 \%$ to $50 \%$ of pediatric patients who had AKI show signs of chronic renal insufficiency, indicating that sublethal injury permanently alters the renal bed (27). We observed normalization of both markers (SCr and $\mathrm{ClCr}$ ) before discharge patient from the hospital. Our finding of the marked difference in estimated $\mathrm{ClCr}(\mathrm{eClCr})$ and measured $\mathrm{ClCr}(\mathrm{mClCr})$ 80,98 vs. $39,88 \mathrm{ml} / \mathrm{min} . / 1,73 \mathrm{~m}^{2}$ are consistent with results published by Harrison MA. et al. (28). They studied 14 neonates undergoing open heart surgery and find that the median overestimation of $\mathrm{ClCr}$ by the Schwartz formula was $58 \%$. The difference between $\mathrm{mClCr}$ and eClCr authors explain due to diminished renal blood flow, postoperative ventricular dysfunction, reperfusion injury, and the systemic inflammatory response triggered by CPB. Evidence supports an independent association between the duration of CPB and the development of CPB related AKI (28). In general, the longer the duration of extracorporeal support, the higher the risk of coagulopathy, the need for transfusion support, gut hypoperfusion, renal ischemia and AKI. There is no single defined threshold time during CPB beyond which the incidence of AKI increases dramatically. Future studies may better define a safe time limit during CPB to decrease perfusion related AKI.

\section{CONCLUSIONS}

Open heart surgery is associated with a high risk for developing AKI. This complication is associated further with substantial morbidity and mortality. The pathogenesis of kidney injury during CPB is complex and involves hemodynamic, inflammatory, and other mechanisms that interact at a cellular level. At present, no pharmacologic interventions have demonstrated conclusively efficacy in the prevention of renal dysfunction after cardiac surgery. More important is to prevent development of AKI preserving autoregulation of renal perfusion to avoid ischemic injury. The incidence of AKI in our group of patients according the KDIGO definition was 46,6\% (14/30), however they did not require application of any form of RRT. Schwartz formula overestimates $\mathrm{ClCr}$ and reliance on eClCr could result in toxic concentrations of drugs eliminated by the kidneys. Short-time outcome (till one months) shows that in the population studied, these changes have a severe, but transient effect and renal biomarkers (SCr and $\mathrm{ClCr}$ ) return to normal values at the time of discharge the patient from hospital.

\section{Conflict of interest: None}

\section{REFERENCES:}

1. Rigden SPA, Barratt TM, Dillon MJ (1982) Acute renal failure complicating cardiopulmonary bypass surgery. Arch Dis in Childh;57, 425-430

2. Giuffre RM, Tam KH, Williams WW et al (1992) Acute renal failure complicating pediatric cardiac surgery: A comparison of survivors and nonsurvivors following acute peritoneal dialysis. Pediatr Cardiol;13:208-213

3. Dittrich S, Kurschat K, Dähnert I et al (2000) Renal function after cardiopulmonary bypass surgery in cyanotic congenital heart disease. Int Journ of Cardiol;73:2, 173-179

4. Kist-van Holthe tot Echten JE, Goedvolk CA, Doornaar van der Vorst MMJ et al (2001) Acute renal insufficiency and renal replacement therapy after pediatric cardiopulmonary bypass surgery. Pediatr Cardiol; 22:32 l-326

5. Mishra J, Dent C, Tarabishi R et al (2005) Neutrophil gelatinase-associated lipocalin (NGAL) as a biomarker for acute renal injury after cardiac surgery Lancet; 365:1231-1238 
6. Skippen PW, Krahn GE (2005) Acute Renal Failure in Children Undergoing Cardiopulmonary Bypass. Crit Care Resusc;7:286-291

7. Kuitunen A, Vento A, Suojaranta-Ylinen R et al (2006) Acute Renal Failure After Cardiac Surgery: Evaluation of the RIFLE Classification. Ann Thorac Surg;81:542-546.

8. Bennett M, Dent CL, Ma Q, et al (2008) Urine NGAL Predicts Severity of Acute Kidney Injury After Cardiac Surgery: A Prospective Study. Clin J Am Soc Nephrol:3: 665-673

9. Blinder JJ, Goldstein SL, Lee VV et al (2012) Congenital heart surgery in infants: Effects of acute kidney injury on outcomes. J Thorac Cardiovasc Surg; 143:368-374

10. Zappitelli M, Bernier P-L, Saczkowski RS et al (2009) A small post-operative rise in serum creatinine predicts acute kidney injury in children undergoing cardiac surgery. Kidney Int; 76, 885892

11. Goldstein SL, Chang AC (2006) Fluid balance in children after cardiac surgery: Is fenoldopam an answer? Pediatr Crit Care Med;7:89-90

12. Picca S, Principato F, Mazzera E et al (1995) Risks of acute renal failure after cardiopulmonary bypass surgery in children: a retrospective 10-year casecontrol study. Nephrol Dial Transplant;10:630-636

13. Krawczeski CD, Goldstein SL, Woo JG et al (2011) Temporal Relationship and Predictive Value of Urinary Acute Kidney Injury Biomarkers After Pediatric Cardiopulmonary Bypass. JACC; 58:22,2301-2309

14. Liu KD, Altmann C, Smits G et al (2009) Serum interleukin-6 and interleukin-8 are early biomarkers of acute kidney injury and predict prolonged mechanical ventilation in children undergoing cardiac surgery: a case-control study. (2009) Crit Care; 13:R104

15. Beger RD, Holland RD, Sun J et al (2008) Metabonomics of acute kidney injury in children after cardiac surgery. Pediatr Nephrol;23:977-984

16. Schwartz GJ, Muñoz A, Schneider MF et al (2009) New Equations to Estimate GFR in Children with CKD. J Am Soc Nephrol; 20(3):629-637

17. Bellomo R, Auriemma S, Fabbri A, et al (2008) The pathophysiology of cardiac surgery-associated acute kidney injury (CSA-AKI). Int J Artif Organs;31:1 $66-78$.

18. Bellomo R, Ronco C, Kellum JA et al (2004) Acute renal failure - Definition, outcome measures, animal models, fluid therapy and information technology needs: The Second International Consensus Conference of the Acute Dialysis Quality Initiative (ADQI) Group. Crit Care; 8:R204-R212

19. Palmieri T, Lavrentieva A, Greenhalgh D (2009) An assessment of acute kidney injury with modified RIFLE criteria in pediatric patients with severe burns. Intensive Care Med; 35:2125-2129

20. Akcan-Arikan A, Zappitelli M, Loftis LL et al (2007) Modified RIFLE criteria in critically ill children with acute kidney injury. Kidney Int;71,1028-1035

21. Kidney Disease: Improving Global Outcomes (KDIGO) Acute Kidney Injury Work Group. (2012) KDIGO Clinical Practice Guideline for Acute Kidney Injury. Kidney inter, Suppl.; 2: 1-138

22. Heilbron DC, Holliday MA, AI-Dahwi A et al (1991) Expressing glomerular filtration rate in children. Pediatr Nephrol;5:5-11

23. Zaffanello M, Franchini M, Fanos V (2007) Is Serum Cystatin-C a Suitable Marker of Renal Function in Children? Ann Clin Lab Sci;37:233-239

24. Ho J, Lucy M, Krokhin O et al. (2009) Mass spectrometry-based proteomic analysis of urine in acute kidney injury following cardiopulmonary bypass: a nested case-control study. Am J Kidney Dis; 53:584-595

25. Sear JW (2005) Kidney dysfunction in the postoperative period. Brit Journ of Anaesth; 95:2032

26. Uchino S, Kellum JA, Bellomo R et al (2005) Acute renal failure in critically ill patients: A multinational, multicenter study. JAMA; 294:813-818

27. Askenazi DJ, Feig DI, Graham NM et al (2006) 3-5 year longitudinal follow-up of pediatric patients after acute renal failure. Kidney Int; 69:184-189

28. Harrison MA, Davis S, Eggleston S et al (2003) Serum creatinine and estimated creatinine clearance do not predict perioperatively measured creatinine clearance in neonates undergoing congenital heart surgery. Pediatr Crit Care Med;4:55-59

29. Salis S, Mazzanti VV, Salvi L et al (2008) Cardiopulmonary bypass duration is an independent predictor of mortality and morbidity after cardiac surgery. J Cardiothorac Vasc Anesth;22:814-822

\section{Address:}

Jekabs Krastins

Department of Pediatric Intensive Care and Anaesthesiology,

Children`s University Hospital,

Vienibas gatve 45, Riga

E-mail: krajek@inbox.lv 
Table 1. Demographic data

\begin{tabular}{|l|c|c|c|}
\hline \multicolumn{1}{|c|}{ Variable } & Median & IQR & Range \\
\hline Age, months & 7,5 & $5<10$ & $0,3<26$ \\
\hline Body weight $(\mathrm{kg})$ & 6,4 & $5,2<8,2$ & $2,88<10$ \\
\hline
\end{tabular}

Table 2. Characteristics of patients

\begin{tabular}{|c|c|c|}
\hline Heart leason & No of pts & $\%$ \\
\hline AVSD (Atrioventricular septal defect) & 7 & 23,4 \\
\hline ASD (Atrial septal defect) & 1 & 3,3 \\
\hline VSD (Ventricular septal defect) & 15 & 50,0 \\
\hline TAPVD (Total anomalous pulmonary vein drainage) & 1 & 3,3 \\
\hline TGA (Transposition of great arteries) & 3 & 10,0 \\
\hline TOF (Tetralogy of Fallot) & 3 & 10,0 \\
\hline Total: & 30 & 100,0 \\
\hline
\end{tabular}

Table 3. CPB variables

\begin{tabular}{|l|c|c|c|}
\hline \multicolumn{1}{|c|}{ Variable } & Median & IQR & Range \\
\hline CPB time (min.) & 147 & $116,75<205$ & $50<286$ \\
\hline Aortic cross-clamping time (min.) & 95 & $70,5<133$ & $25<185$ \\
\hline Lowest body temperature $\left(\mathrm{C}^{\circ}\right)$ & 29,75 & $27,48<30,83$ & $19<32$ \\
\hline Urine output $(\mathrm{ml} / \mathrm{kg} / \mathrm{h})$ & 2,41 & $1,29<3,15$ & $0,47<7,76$ \\
\hline
\end{tabular}

Table 4. Perioperative changes in $\mathrm{SCr}$ and $\mathrm{CrCl}$

\begin{tabular}{|c|c|c|c|c|}
\hline Variable & Before surgery & After CPB & Before discharge & P \\
\hline $\mathrm{SCr}(\mu \mathrm{mol} / \mathrm{l})$ & $29(24<32,9)$ & $35(27,5<50,5)$ & $23(19,3<26,75)$ & $<0,0001$ \\
\hline $\begin{array}{c}\mathrm{eClCr}(\mathrm{ml} / \mathrm{min} . / 1,73 \\
\left.\mathrm{m}^{2}\right)\end{array}$ & $\begin{array}{c}98,43 \\
(89,57<123,04)\end{array}$ & $\begin{array}{c}80,98 \\
(60,73<97,97)\end{array}$ & $124,80(104,25<145,24)$ & $<0,0001$ \\
\hline $\begin{array}{c}\mathrm{mClCr}(\mathrm{ml} / \mathrm{min} . / 1,73 \\
\left.\mathrm{m}^{2}\right)\end{array}$ & $\begin{array}{c}39,88 \\
(21,96<67,82)\end{array}$ & & $0,0042^{*}$ \\
\hline
\end{tabular}

* mClCr versus eClCr (Fig. 3)

Table 5. Incidence af AKI according to KDIGO criteria.

\begin{tabular}{|c|c|c|c|}
\hline \multicolumn{2}{|c|}{ Variable $($ Median $[\mathrm{IQR}])$} & Stage I $(\mathrm{n}=9)$ & Stage II and III $(\mathrm{n}=5)$ \\
\hline \multirow{2}{*}{$\begin{array}{c}\text { SCr } \\
\text { increase }\end{array}$} & Absolute in $\mu \mathrm{mol} / \mathrm{l}$ & $15,00(11,2<24,68)$ & $38,91(28,90<52,34)$ \\
\cline { 2 - 4 } & Rise $(\%)$ from baseline & $65,22(58,26<83,45)$ & $228,88(139,40<266,64)$ \\
\hline
\end{tabular}



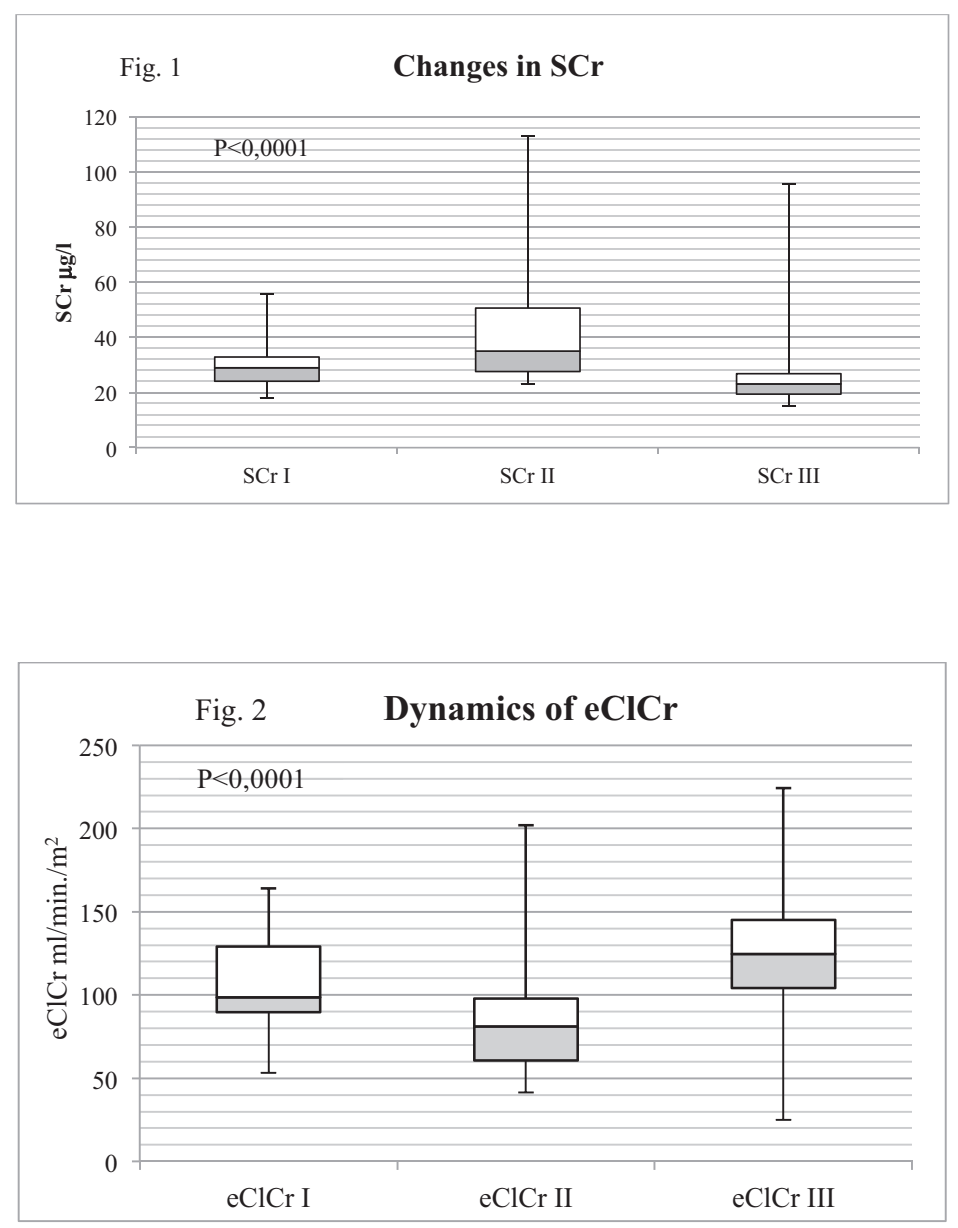

Fig. 3 Estimated ClCr vs. measured $\mathrm{ClCr}$

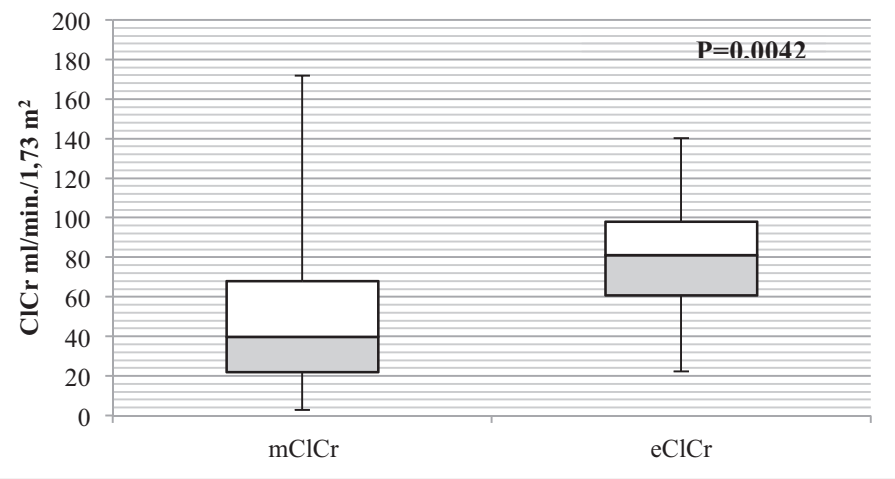

